\title{
The Value of Magnetic Resonance Imaging For Staging and Planning Breast-Conserving Surgery
}

\author{
Elçin Ersöz Köse ${ }^{1}$, Leyla Özel2 ${ }^{2}, \odot$ Gökay Reyhan ${ }^{1}, \odot$ Pınar Ata $^{3}$, $\odot$ Hikmet Karagüllü ${ }^{4}$, \\ Gamze Kılıçoğlu ${ }^{4}$ \\ ${ }^{1}$ Department of Thoracic Surgery, Health Science University, Sultan Abdulhamid Han Training and Research Hospital, Istanbul, Turkey \\ ${ }^{2}$ Department of General Surgery, Bahcesehir University Faculty of Medicine, Istanbul, Turkey \\ ${ }^{3}$ Department of Molecular Genetics and Typing Tissue, Health Science University, Haydarpasa Numune Training and Research Hospital, \\ Istanbul, Turkey \\ ${ }^{4}$ Department of Radiology, Health Science University, Haydarpasa Numune Training and Research Hospital, Istanbul, Turkey
}

\begin{abstract}
Introduction: This study aimed to evaluate the effect of breast magnetic resonance imaging (MRI) on staging and surgical planning.

Methods: Ninety-two females with breast cancer were enrolled in the study. We prospectively evaluated the contribution of MRI compared to mammography (MMG) and ultrasonography (USG) and impact of MRI on surgical treatment and histopathological concordance.

Results: Contribution of breast MRI to the workup and management of breast cancer in our institute was meaningful by upstaging the cases in 23/92 (25\%) of the patients and suggesting a change in surgical plan in 21/92 (23\%) of the patients. Surgical staging with breast MRI results correlated with the final pathological staging in 18/21 (85\%) patients who had a change in surgical plan.

Discussion and Conclusion: The primary therapy modality of early breast cancer is surgery. The overall tumor size, the relationship between tumor size and breast size, tumor localization, tumor stage, and histopathological findings help to shape surgical management. MRI was better than conventional diagnostic techniques in determining correct tumor diameter and in detecting non-invasive cancer areas. Consequently preoperative breast MRI is an important adjunct to conventional imaging (USG and MMG) in the staging of breast cancer and a useful tool in treatment planning.

Keywords: Breast cancer; breast-conserving surgery; magnetic resonance imaging; staging of breast cancer.
\end{abstract}

B reast cancer is the most common cancer among females, and its incidence is constantly increasing. The standard procedure is breast-conserving surgery (BCS) with wide local excision in women with early-stage breast cancer who are thought to have a single and resectable tumor as determined by clinical examination and conven- tional imaging. Mapping of local disease is the key element to guide optimal surgery to get tumor-free margins ${ }^{[1]}$.

The usual preoperative workup of breast malignancy consists of clinical breast examination and mammography (MMG) with ultrasound (USG) [1]. MMG and breast USG have been generally used as primary conventional imaging

Correspondence (İletişim): Elçin Ersiz Köse, M.D. Saglik Bilimleri Universitesi, Sultan Abdulhamid Han Egitim ve Arastirma Hastanesi, Gogus Cerrahisi Klinigi, Istanbul, Turkey

Phone (Telefon): +90 5309647292 E-mail (E-posta): elcinersoz@hotmail.com

Submitted Date (Başvuru Tarihi): 05.12.2017 Accepted Date (Kabul Tarihi): 11.05.2018

Copyright 2019 Haydarpaşa Numune Medical Journal

OPEN ACCESS This is an open access article under the CC BY-NC license (http://creativecommons.org/licenses/by-nc/4.0/) 
modalities for the diagnosis of breast cancer. MMG is the best screening modality in postmenopausal women, but its sensitivity is lower in young women with a high genetic risk or dense breasts. Furthermore, conventional imaging and clinical examination frequently underestimate tumor size and multifocality ${ }^{[2]}$.

Breast magnetic resonance imaging (MRI) is a complementary diagnostic modality in breast imaging with reported accuracy of $100 \%$ for invasive breast cancer, and $40 \%-$ $100 \%$ for ductal carcinoma in situ (DCIS) ${ }^{[3-5]}$.

The major advantage of MRI is its high sensitivity in the diagnosis of invasive carcinomas. Its limitations include its moderate sensitivity in the diagnosis of in situ carcinomas and its low specificity ${ }^{[6,7]}$. The high sensitivity of MRI has proven useful in the detection of multifocal lesions and contralateral carcinomas ${ }^{[8-10]}$. MRI has been increasingly used in the preoperative evaluation of both the ipsilateral and contralateral breast in patients newly diagnosed with breast cancer ${ }^{[11-13]}$. Breast MRI is commonly used in local staging and planning the surgical management of breast cancer. Therefore, potential benefit of preoperative breast MRI is a better selection of the patients suitable for BCS ${ }^{[14]}$. This study aimed to evaluate whether performing preoperative breast MRI had an effect on the preoperative staging of breast cancer and planning the surgical approach for patient.

\section{Materials and Methods}

The consecutive 92 women with a diagnosis of earlystage breast cancer (age 27-69 years) were enrolled in this prospective study between 2010 and 2013 in the general surgery department of Haydarpasa Numune Hospital. The patients with contralateral breast cancer and those undergoing neoadjuvant chemotherapy prior to surgical excision were excluded. Prior to study, all patients underwent clinical breast examination, conventional breast imaging (MMG, USG), and MRI.

The diagnosis was confirmed by fine-needle aspiration cytology or percutaneous core biopsy, including USG-guided procedures, or excisional biopsy, followed by MRI prior to definitive surgical treatment.

For each case, surgical approach was first chosen according to conventional imaging and clinical evaluation and subsequent fine-needle cytology/core biopsies of suspicious lesions; afterwards, the surgeons and radiologists redefined the treatment plan on the basis of results of MRI. Surgical treatment was based on the extent of the disease, the number of tumor foci, and the breast size.

The management decision was changed from lumpectomy to mastectomy due to multicentric or extensive multifocal disease detected on MRI. Lumpectomy was changed to a wider excision because the primary lesion was detected as multifocal or more extensive on MRI.

\section{MRI Technique}

Breast MRI was performed with the patient in the prone position in a 3.0 Tesla MRI system (Philips Achieva; Philips Healthcare, the Netherlands). Three-dimensional, fatsuppressed, gradient-echo, contrast material- enhanced, dynamic imaging before and seven times after a bolus injection of $0.1 \mathrm{mmol} / \mathrm{kg}$ of gadopentetate dimeglumine (Gadovist; Berlex, Wayne, NJ, USA) were performed in the sagittal plane.

If the lesion had a spiculated, ill-defined, or micro-lobulated margin, it was regarded as a morphologically suspicious lesion. Findings with non-mass-like enhancements, including linear, ductal, and segmental patterns, were considered suspicious lesions. Findings with a kinetic pattern showing an early rise and an early washout were regarded as kinetically suspicious lesions. All patients had a breast MRI after histologic confirmation of the index breast cancer, and the final classification of additional MRI-detected suspicious lesions was made without knowledge of the histologic findings.

Multifocality was defined as the presence of additional disease in same quadrant of the breast tissue, while multicentricity was defined as the additional disease within another quadrant of the breast tissue.

\section{Surgical Methods}

BCS (lumpectomy, wide excision, or quadrantectomy) was performed for single or multifocal lesions allowing a single excision. We defined lumpectomy as the surgical excision of a tumor with the removal of a minimal amount of surrounding tissue. 'We excised area near the tumor to obtained the clean surgical area, so we made wide excision. All surgical procedures were carried out with intraoperative frozen sections. Mastectomy was preferred in case of large or multicentric tumors, or retroareolar tumor.

\section{Histopathological Evaluation}

Histopathological evaluation of the specimens was made according to the classification published by the American Joint Committee on Cancer (TNM-AJCC) in 2010. Surgical breast specimens were evaluated at $0.5 \mathrm{~cm}$ intervals parallel to the line drawn between the nipple head and the tumor. After the mastectomy or quadrantectomy operation, detailed histopathological evaluation must be made 
on the specimen to find additional cancer focus areas into parenchyma surrounding the tumor.

Unifocal disease is a single focus in the mammary gland. Multifocal disease is the presence of two or more malignant foci in the same quadrant. Multicentric disease is the presence of one or more tumor foci in different quadrants.

Local recurrence of breast cancer after conservation surgery is determined primarily by the adequacy of surgical margins. There is no alliance in the literature regarding to surgical margin width for safe surgery. It is the practice of many North American and European surgeons to undertake re-excision when residual cancer within $2 \mathrm{~mm}$ of a surgical margin is determined by histopathologic examination [15]. In our study, we defined a clean margin of greater than $2 \mathrm{~mm}$ as the tumor negative margins.

\section{Results}

The breast pathologies of 92 patients were evaluated with bilateral USG, MMG, and MRI. The mean age of the patients was 49.6 years. Eight percent of the patients had negative breast examination. The mean number of births of the patients was 2.6. First delivery was before 30 years of age in $90 \%$ of the patients. The rate of non-breastfeeding patients was $5 \%$, and $24 \%$ had a family history of breast cancer. Of all the patients, 54\% were postmenopausal, 30\% were using oral contraceptives, and $10 \%$ were using hormone replacement therapy. Ten percent of the patients underwent surgery for breast cancer and another $10 \%$ for benign conditions. Postoperative histopathological diagnosis of the patients, invasive ductal carcinoma (75\%), invasive lobular carcinoma (8\%), DCIS (8\%), inflammatory carcinoma (3\%), mixed-type carcinoma (3\%), and basaloid-type carcinoma (3\%).

All patients $(n=92)$ were analyzed with conventional imaging as stage I and II. MRI upstaged the disease in 23 cases (25\%), and treatment plan was changed from breast conservation to mastectomy in 8 of them. Thirteen cases had no stage change but also had mastectomy instead of breast conservation because of additional MRI findings of multicentricity $(n=5)$, multifocality $(n=2)$, larger size $(n=2)$, involvement of nipple-areolar complex with retroareolar location $(n=2)$, and extensive DCIS $(n=2)$. Histopathology confirmed the presence of mammary carcinoma in all 92 patients. Pathological correlation was detected in 11 of 13 cases $(84.6 \%)$ with mastectomy due to MRI findings and in 7 of 8 cases with mastectomy due to stage increase (87.5\%). Two cases were multifocal and five were multicentric as suggested by MRI. Three of 21 patients (14\%) had no pathological correlation. One of three patient underwent surgical resection 6 weeks after the first operation because of the surgical margin was positive in the subsequent pathology report (paraffin sections). Two of three patients received oncologic treatment because the patients did not accept the second operation.

In 21 patients, treatment plan was changed from breast conservation surgery to mastectomy. As a result of MRI, findings were multifocality $(n=3)$, multicentricity $(n=11)$, subareolar extension $(n=2)$, larger tumor $(n=2)$, pectoral muscle invasion $(n=1)$, and extensive DCIS component $(n=2)$. The stage increased in 8 of 21 patients. The stage increased from stage I to stage IIA in six of eight patients, from stage I to stage IIIB in one of eight patients, and from stage IIA to stage IIB in one of eight patients. Postoperative histopathological diagnosis of these 21 patients: invasive ductal carcinoma (38.2\%), invasive lobular carcinoma (52.3\%), and DCIS (9.5\%).

The primary outcomes of our study were that breast MRI significantly changed the workup in our patients, upstaged the cancer in $25 \%$ of our patients (23/92), and changed the surgical plan in $23 \%$ of our patients (21/92). All surgical plan changes were from Breast Conservation Treatment (BCT) to a mastectomy, with or without axillary lymph node dissection. Pathological correlation with MRI findings was recorded in $86 \%$ of the cases with mastectomy. Table 1 describes all 21 patients with a change in their surgical plan.

\section{Discussion}

Surgery is the primary therapy modality of early breast cancer. The overall tumor size, the relationship between tumor size and breast size, tumor localization, tumor stage and histopathological findings help to shape surgical management. MRI was better than conventional diagnostic techniques in determining correct tumor diameter and in detecting non-invasive cancer areas.

The major advantage of MRI is its high sensitivity in the diagnosis of invasive carcinoma ${ }^{[3-5]}$. This is underscored in a recent study by Fischer et al that determined a 93\% sensitivity for MRI in comparison with $58 \%$ for palpation, $86 \%$ for conventional MMG, and 75\% for USG. MRI's specificity is more problematical. Data reported by Fischer suggested that specificity is $76 \%$ for palpation, $32 \%$ for $M M G, 80 \%$ for USG, and only $65 \%$ for MRI ${ }^{[10]}$.

The high sensitivity of MRI has proven useful in the detection of multifocal lesions and contralateral carcinomas ${ }^{[8,9]}$. According to Mumtaz et al, MRI provides more accurate findings regarding tumor size than either conventional MMG or USG [16]. MMG, although used as a basic breast 
Table I. Patients with changed treatment plans due to breast MRI findings

\begin{tabular}{|c|c|c|c|c|c|c|}
\hline Patient no & $\begin{array}{c}\text { Stage before } \\
\text { MRI }\end{array}$ & $\begin{array}{l}\text { Stage after } \\
\text { MRI }\end{array}$ & $\begin{array}{l}\text { Surgical plan } \\
\text { before MRI }\end{array}$ & $\begin{array}{l}\text { Surgical desicion } \\
\text { after MRI }\end{array}$ & $\begin{array}{l}\text { Why the operative } \\
\text { procedure has changed? }\end{array}$ & $\begin{array}{c}\text { Corelation with } \\
\text { Pathology }\end{array}$ \\
\hline 3 & Stage I & Stage I & BCS & Mastectomy & Multifocal & Yes \\
\hline 5 & Stage IIA & Stage IIA & BCS & Mastectomy & Larger tumour & Yes \\
\hline 6 & Stage I & Stage IIA & $\mathrm{BCS}$ & Mastectomy & Multicentric & Yes \\
\hline 19 & Stage I & Stage I & $\mathrm{BCS}$ & Mastectomy & ExtensiveDCIScomponent & Yes \\
\hline 20 & Stage I & Stage I & BCS & Mastectomy & ExtensiveDCIScomponent & Yes \\
\hline 21 & Stage I & Stage I & $\mathrm{BCS}$ & Mastectomy & Subareolar extension & Yes \\
\hline 23 & Stage I & Stage I & BCS & Mastectomy & Multicentric & Yes \\
\hline 37 & Stage I & Stage IIA & BCS & Mastectomy & Multifocal & Yes \\
\hline 44 & Stage IIA & Stage IIB & BCS & Mastectomy & Multicentric & Yes \\
\hline 50 & Stage I & Stage IIA & BCS & Mastectomy & Multicentric & Yes \\
\hline 51 & Stage IIA & Stage IIA & BCS & Mastectomy & Multicentric & Yes \\
\hline 56 & Stage IIA & Stage IIA & BCS & Mastectomy & Multicentric & Yes \\
\hline 61 & Stage I & Stage IIA & $\mathrm{BCS}$ & Mastectomy & Multicentric & Yes \\
\hline 62 & Stage I & Stage IIA & $\mathrm{BCS}$ & Mastectomy & Multicentric & Yes \\
\hline
\end{tabular}

BCS: Breast conserving surgery; Multifocal: Additional disease burden within the same quadrant of breast tissue; Multicentric: Additional disease burden within another quadrant of breast tissue.

imaging, shows the tumor size smaller than its real size.

Tumor size is a parameter for surgical treatment planning. However, tumor localization must also be considered in BCS planning. Accurate evaluation of the tumor size and examination of the whole breast is of extreme importance for optimal treatment planning.

Breast cancer recurrence after BCS is reported in 3\%-19\% of patients and is mostly due to incomplete resection or multifocality ${ }^{[17,18]}$. Positive tumor margins after lumpectomy are seen in $40 \%-70 \%{ }^{[19]}$. DCIS can be present in and around an invasive cancer, and extensive intraductal component is more frequently accused for recurrence after tumorectomy [20].

MMG is less sensitive in detection of breast cancer in patients with dense breast parenchyma and tumor margins can be obscured ${ }^{[21]}$. The role of USG in detecting multifocal or multicentric lesions is yet not well defined. USG can give a good estimation of the diameter of an invasive mass, but DCIS around the mass is often underestimated ${ }^{[22,23]}$.

As sensitivity of MMG is lower in patients with dense breast parenchyma, USG and MRI could be useful especially in this group of patients ${ }^{[21]}$. On the other side, dense breast tissue can be a consequence of fibrocystic proliferation, which could enhance on MRI, leading to false-positive examinations and unnecessary wider excisions.

Some studies have shown that MRI is more sensitive than conventional methods for detection of multiple malignant foci and DCIS surrounding invasive carcinoma, especially in women with fibroglandular and dense mammary parenchyma ${ }^{[2,24,25]}$. Studies have shown that sensitivity of MRI for detection of DCIS is $60 \%-90 \%$ [26,27]. According to some authors, MRI has priority upon other imaging techniques if there was abundant intraductal component within the tumor ${ }^{[16,28]}$.

For the last decade, MRI has been widely used for breast carcinoma diagnosis as a routine at many breast centers. Ninety-four percent of radiologists have reported that MRI is useful for accurate staging ${ }^{[29]}$. Herein with MRI, 23 out of 92 patients were analyzed as increase in stage, and 8 of those 23 patients had change in treatment modality from BCS to mastectomy. Thirteen patients without stage change also had mastectomy because of additional findings detected in MRI as the treatment of choice rather than BCS. 
Some authors reported the advantages of MRI at preoperative local staging in breast cancer. MRI has been found superior to other techniques for detecting tumor volume, multicentric-multifocal state, and the tumor at the contralateral side ${ }^{[10,28,30,31]}$. We diagnosed 20 patients with multifocal or multicentric tumors. We used MRI in 20 patients (20/20) (100\%), MMG in 7 patients (7/20) (35\%), and USG in 6 patients (6/20) (30\%) for diagnosis. As a conclusion, MRI is more accurate in diagnosis of multifocality at dense mammary glands ${ }^{[25]}$.

In our study, 13 patients without stage change had suspicious additional findings with MRI, and treatment modality of these patients had changed from BCS to mastectomy after MRI. Those findings resulting in decision changes were multicentric disease in five patients, multifocal disease in two, larger tumor size in two, retroareolar tumor with nipple involvement in two, and disseminated DCIS in two.

Tillman et al. ${ }^{[32]}$ compared MMG and MRI in 212 patients with breast carcinoma undergoing BCS. According to MRI results, $11 \%$ of cases had a change in the treatment approach. In another study, $16 \%$ of 267 patients who had preoperative MRI had mastectomy rather than BCS [33].

Breast MRI contributed significantly to the workup and management of breast cancer at our institution, suggesting a higher stage in 23/92 (25\%) patients and changing the surgical plan in 21/92 (23\%) patients. Breast MRI results correlated with the final pathology in $18 / 21$ patients (85\%) who had a change in surgical plan.

Herein $23 \%$ ratio of change in surgical treatment modality we observed was higher when compared with the results in literature. This might be due to the lower socioeconomic and educational states of our patients and our treatment decision of larger and multifocal tumors as mastectomy, their lower compliance for radiotherapy sessions, and intimate follow-up visits that are obligatory after BCS.

Extensive intraductal component (EIC) is known as a risk factor that is related with local tumor recurrence ${ }^{[33,34]}$. EIC was first described at the beginning of 1980s ${ }^{[35]}$. Neff et al. [36] reported that local tumor recurrence was $15 \%$ with EIC and $8 \%$ without EIC. Holland et al. detected multifocal and multicentric foci at mastectomy specimens.

As a summary of the results from the literature, MRI has found to be an important preoperative imaging technique and could change therapeutic strategy $10 \%-20 \%$. This change covers the extent of the surgical procedure. In one study, preoperative MRI decreased cancer recurrence at ipsilateral side from $6.5 \%$ to $1.2 \%$ and at the contralateral side from $4 \%$ to $1.7 \%[37,38]$.

At 2004, Fischer et al. ${ }^{[39]}$ had studied patients with breast cancer for the long-term results of the disease, 121 patients with MRI and 225 without MRI. They detected statistically significant difference between them. Local recurrence was observed in $1.2 \%$ and contralateral tumor was found in $1.6 \%$ of the patients screened with preoperative MRI, while those ratios were $6.8 \%$ and $4 \%$, respectively, in non-MRI screened patients.

Herein in our study, pathological correlation was detected in 11 of 13 cases (84.6\%) without stage change and in 7 of 8 cases with stage increase (87.5\%). A total of $18 / 21$ patients had pathological correlation (85.7\%).

$\mathrm{BCS}$ is the primary therapy for most of the patients with early-stage breast cancer. Local excision of the tumor with a clean surgical margin with good cosmetic results is the accepted technique. The success of the BCS depends on good local control of the disease and establishment of the balance between the cosmesis and life quality. For the local control of the disease, correct staging and appropriate surgical choice have pivotal importance. Although there is a risk of MRI to cause detection of the tumor size larger than real and increase the extent of surgical resections, herein we suggest the use of MRI with other conventional methods.

\section{Conclusion}

In patients who have histologically diagnosed breast cancer, MRI is a better tool in providing information about the condition of the ipsilateral and contralateral breast in both planned BCS and mastectomy. Today, the use of MRI in staging of patients with breast cancer and BCS decision positively affects the patient's survey.

Ethics Committee Approval: The study was approved by the local Ethics Committee of the Health Science University, Haydarpasa Numune Education and Research Hospital, and conducted in accordance with the ethical principles stated in the Declaration of Helsinki.

Peer-review: Externally peer-reviewed.

Authorship Contributions: Concept: E.E.K., L.Ö., G.R., P.A., H.K., G.K.; Design: E.E.K., L.Ö., G.R., P.A., H.K., G.K.; Data Collection or Processing: E.E.K., L.Ö., G.R., P.A., H.K., G.K.; Analysis or Interpretation: E.E.K., L.Ö., G.R., P.A., H.K., G.K.; Literature Search: E.E.K., L.Ö., G.R., P.A., H.K., G.K.; Writing: E.E.K., L.Ö., G.R., P.A., H.K., G.K.

Conflict of Interest: None declared.

Financial Disclosure: The authors declared that this study received no financial support. 


\section{References}

1. Kulkarni S, Singh N, Crystal P. Preoperative breast magnetic resonance imaging: applications in clinical practice. Can Assoc Radiol J 2012;63:207-14. [CrossRef]

2. Schelfout K, Van Goethem M, Kersschot E, Colpaert C, Schelfhout AM, Leyman P, et al. Contrast-enhanced MR imaging of breast lesions and effect on treatment. Eur J Surg Oncol 2004;30:501-7. [CrossRef]

3. Heywang-Köbrunner SH. Contrast-enhanced magnetic resonance imaging of the breast. Invest Radiol 1994;29:94-104.

4. Gilles R, Guinebretière JM, Lucidarme $O$, Cluzel P, Janaud G, Finet JF, et al. Nonpalpable breast tumors: diagnosis with contrast-enhanced subtraction dynamic MR imaging. Radiology 1994;191:625-31. [CrossRef]

5. Kaiser WA. MR mammography. Der Radiologe 1993;33:292-8.

6. Gilles R, Zafrani B, Guinebretière JM, Meunier M, Lucidarme O, Tardivon AA, et al. Ductal carcinoma in situ: MR imaginghistopathologic correlation. Radiology 1995;196:415-9.

7. Fischer U, Westerhof JP, Brinck U, Korabiowska M, Schauer A, Grabbe E. Ductal carcinoma in situ in dynamic MR-mammography at 1.5 T. [Article in German]. Rofo 1996;164:290-4.

8. Rieber A, Merkle E, Böhm W, Brambs HJ, Tomczak R. MRI of histologically confirmed mammary carcinoma: clinical relevance of diagnostic procedures for detection of multifocal or contralateral secondary carcinoma. J Comput Assist Tomogr 1997;21:773-9. [CrossRef]

9. Fischer U, Vosshenrich R, Probst A, Burchhardt H, Grabbe E. Preoperative MR-mammography in diagnosed breast carcinoma. Useful information or useless extravagance?. [Article in German]. Rofo 1994;161:300-6. [CrossRef]

10. Fischer U, Kopka L, Grabbe E. Breast carcinoma: effect of preoperative contrast-enhanced MR imaging on the therapeutic approach. Radiology 1999;213:881-8. [CrossRef]

11. Lee SG, Orel SG, Woo IJ, Cruz-Jove E, Putt ME, Solin LJ, et al. MR imaging screening of the contralateral breast in patients with newly diagnosed breast cancer: preliminary results. Radiology 2003;226:773-8. [CrossRef]

12. Liberman L, Morris EA, Kim CM, Kaplan JB, Abramson AF, Menell $\mathrm{JH}$, et al. MR imaging findings in the contralateral breast of women with recently diagnosed breast cancer. AJR Am J Roentgenol 2003;180:333-41. [CrossRef]

13. Viehweg $P$, Rotter K, Laniado M, Lampe D, Buchmann J, Kölbl $\mathrm{H}$, et al. MR imaging of the contralateral breast in patients after breast-conserving therapy. Eur Radiol 2004;14:402-8.

14. Pediconi F, Catalano C, Padula S, Roselli A, Moriconi E, Dominelli $V$, et al. Contrast-enhanced magnetic resonance mammography: does it affect surgical decision-making in patients with breast cancer? Breast Cancer Res Treat 2007;106:65-74.

15. Anderson DK, Billiar TR, Dunn DC, Hunter JG, Matthews JB, Pollock RE. Schwartz's Principles of Surgery. 10th ed. United States of America: McGraw-Hill Education; 2015. p. 497-565.

16. Mumtaz H, Hall-Craggs MA, Davidson T, Walmsley K, Thurell W, Kissin MW, et al. Staging of symptomatic primary breast cancer with MR imaging. AJR Am J Roentgenol 1997;169:417-24.
17. Winchester DP, Cox JD. Standards for diagnosis and management of invasive breast carcinoma. American College of Radiology. American College of Surgeons. College of American Pathologists. Society of Surgical Oncology. CA Cancer J Clin 1998;48:83-107. [CrossRef]

18. Ghossein NA, Alpert S, Barba J, Pressman P, Stacey P, Lorenz E, et al. Breast cancer. Importance of adequate surgical excision prior to radiotherapy in the local control of breast cancer in patients treated conservatively. Arch Surg 1992;127:411-5.

19. Schmidt-Ullrich $R$, Wazer DE, Tercilla O, Safaii H, Marchant DJ, Smith TJ, et al. Tumor margin assessment as a guide to optimal conservation surgery and irradiation in early stage breast carcinoma. Int J Radiat Oncol Biol Phys 1989;17:733-8. [CrossRef]

20. Holland R, Connolly JL, Gelman R, Mravunac M, Hendriks $\mathrm{JH}$, et al. The presence of an extensive intraductal component following a limited excision correlates with prominent residual disease in the remainder of the breast. J Clin Oncol 1990;8:113-8. [CrossRef]

21. Mandelson MT, Oestreicher N, Porter PL, White D, Finder CA, Taplin $\mathrm{SH}$, et al. Breast density as a predictor of mammographic detection: comparison of interval- and screen-detected cancers. J Natl Cancer Inst 2000;92:1081-7. [CrossRef]

22. Fornage BD, Toubas $\mathrm{O}$, Morel M. Clinical, mammographic, and sonographic determination of preoperative breast cancer size. Cancer 1987;60:765-71. [CrossRef]

23. Satake H, Shimamoto K, Sawaki A, Niimi R, Ando Y, Ishiguchi T, et al. Role of ultrasonography in the detection of intraductal spread of breast cancer: correlation with pathologic findings, mammography and MR imaging. Eur Radiol 2000;10:1726-32.

24. Sardanelli F, Giuseppetti GM, Panizza P, Bazzocchi M, Fausto A, Simonetti G, et al. Sensitivity of MRI versus mammography for detecting foci of multifocal, multicentric breast cancer in Fatty and dense breasts using the whole-breast pathologic examination as a gold standard. AJR Am J Roentgenol 2004;183:1149-57. [CrossRef]

25. Van Goethem M, Schelfout K, Kersschot E, Colpaert C, Verslegers I, Biltjes I, et al. MR mammography is useful in the preoperative locoregional staging of breast carcinomas with extensive intraductal component. Eur J Radiol 2007;62:273-82.

26. Boné $B$, Aspelin P, Bronge $L$, Isberg B, Perbeck $L$, Veress B. Sensitivity and specificity of MR mammography with histopathological correlation in 250 breasts. Acta Radiol 1996;37:208-13.

27. Soderstrom CE, Harms SE, Copit DS, Evans WP, Savino DA, Krakos PA, et al. Three-dimensional RODEO breast MR imaging of lesionscontaining ductal carcinoma in situ. Radiology 1996;201:427-32. [CrossRef]

28. Boetes C, Mus RD, Holland R, Barentsz JO, Strijk SP, Wobbes $\mathrm{T}$, et al. Breast tumors: comparative accuracy of MR imaging relative to mammography and US for demonstrating extent. Radiology 1995;197:743-7. [CrossRef]

29. Bassett LW, Dhaliwal SG, Eradat J, Khan O, Farria DF, Brenner RJ, et al. National trends and practices in breast MRI. AJR Am J Roentgenol 2008;191:332-9. [CrossRef]

30. Oellinger H, Heins S, Sander B, Schoenegg W, Flesch U, Meiss- 
ner R, et al. Gd-DTPA enhanced MRI of the breast: the most sensitive method for detecting multicentric carcinoma in female breast? Eur Radiol 1993;3:223-6. [CrossRef]

31. Orel SG, Schnall MD, Powell CM, Hochman MG, Solin LJ, Fowble BL, et al. Staging of suspected breast cancer: effect of MR imaging and MR-guided biopsy. Radiology 1995;196:115-22.

32. Tillman GF, Orel SG, Schnall MD, Schultz DJ, Tan JE, Solin LJ. Effect of breast magnetic resonance imaging on the clinical management of women with early-stage breast carcinoma. J Clin Oncol 2002;20:3413-23. [CrossRef]

33. Bedrosian I, Mick R, Orel SG, Schnall M, Reynolds C, Spitz FR, et al. Changes in the surgical management of patients with breast carcinoma based on preoperative magnetic resonance imaging. Cancer 2003;98:468-73. [CrossRef]

34. Recht A, Silver B, Schnitt S, Connolly J, Hellman S, Harris JR. Breast relapse following primary radiation therapy for early breast cancer. I. Classification, frequency and salvage. Int J Radiat Oncol Biol Phys 1985;11:1271-6. [CrossRef]

35. Harris JR, Connolly JL, Schnitt SJ, Cady B, Love S, Osteen RT, et al. The use of pathologic features in selecting the extent of surgical resection necessary for breast cancer patients treated by primary radiation therapy. Ann Surg 1985;201:164-9.

36. Neff PT, Bear HD, Pierce CV, Grimes MM, Fleming MD, Neifeld $J P$, et al. Long-term results of breast conservation therapy for breast cancer. Ann Surg 1996;223:709-16. [CrossRef]

37. Hellman S. Stopping metastases at their source. N Engl J Med 1997;337:996-7. [CrossRef]

38. van Tienhoven G, Voogd AC, Peterse JL, Nielsen M, Andersen $\mathrm{KW}$, Mignolet $\mathrm{F}$, et al. Prognosis after treatment for loco-regional recurrence aftermastectomy or breast conserving therapy in two randomisedtrials (EORTC 10801 and DBCG-82TM). EORTC Breast Cancer Cooperative Group and the Danish Breast Cancer Cooperative Group. Eur J Cancer 1999;35:32-8.

39. Fischer U, Zachariae O, Baum F, von Heyden D, Funke M, Liersch T. The influence of preoperative MRI of the breasts on recurrence rate in patients with breast cancer. Eur Radiol 2004;14:1725-31. [CrossRef] 